DOI: $\underline{10.20472 / B M .2016 .4 .1 .004 ~}$

\title{
WORK-LIFE BALANCE IN ACADEMIA: EXPERIENCES OF LECTURERS IN SWITZERLAND
}

\section{ROBERT ALAN LEWIS}

\begin{abstract}
:
This paper investigates the work-life balance experiences of 11 full-time academic lecturers in Switzerland using a case study approach. Open-ended questions in questionnaires were used to gain depth into academic employees' understandings of work-life balance, their experiences in the 'crossover' of work- and life-related obligations, and their perceptions of work-life conflict and time. Findings emphasised the importance of context, due to increased spatial flexibility when working. Findings also shed light on the effects of work-life balance on professional attributes and career-related factors, when evaluating experiences. Conceptually, findings revealed that perceptions of available time are stretched beyond reasonable boundaries. Further research into academic lecturers' experiences attempting to meet work- and non-work-related professional obligations from a larger sample using questionnaires, complemented by interviews, could bring further insight into effects of work-life balance experiences.
\end{abstract}

\section{Keywords:}

Academic work, Careers, Work-life balance, Work-life conflict, Time

JEL Classification: J29

\section{Authors:}

ROBERT ALAN LEWIS, Les Roches Gruyère University of Applied Sciences, Switzerland, Switzerland, Email: ralewis@gmail.com

\section{Citation:}

ROBERT ALAN LEWIS (2016). Work-life balance in academia: Experiences of lecturers in Switzerland. International Journal of Business and Management, Vol. IV(1), pp. 69-84., 10.20472/BM.2016.4.1.004 


\section{Introduction}

Work-life balance was first introduced by Kanter (1977) in her studies on work and family. Schor (1991) also significantly influenced the work-life balance debate through discussions on trade-offs between work and non-work duties. In this paper, work-life balance is defined as the attempt to meet work- and non-work related obligations. Work-life balance, also understood through work-life conflict, has been investigated in terms of its dichotomous, adversary relationship (Friedman and Greenhaus, 2000; Kreiner, Hollensbe and Sheep, 2009). The literature has principally focused on work-life balance issues that have affected workers' difficulties to meet work- and non-work needs (Grzywacz and Carlson, 2006; Manfredi and Holliday, 2004; SHRM, 2003). When focusing on work-life balance in an academic context, studies emphasise traditional employment practices with more maledominated perspectives (Gatta and Roos, 2004; Santos and Cabral-Cardoso, 2008). Maledominated perspectives of work-life balance, in this sense, underscore that working outside of the office has been considered commonplace in academic institutions, regardless of non-work responsibilities, such as in the case of family obligations (Acker and Armenti, 2004; Kinman and Jones, 2008; Santos and Cabral-Cardoso, 2008). These perspectives argue that women traditionally spend more time on family-related duties than men. This model has prevailed in the academic context (Acker and Armenti, 2004), despite evolutions in non-academic sector employment design, which has more consistently addressed worklife balance needs of workers (ibid). Examples include the implementation of flexible working time (SHRM, 2004).

Spatial and temporal flexibility are typical features of academic jobs (Doherty and Manfredi, 2006; Gatta and Roos, 2004; Santos and Cabral-Cardoso, 2008). Recently, studies have shown that this flexibility has also generated overwork and working pattern norms that can lead to increased difficulty to manage work- and non-work obligations (Acker and Armenti, 2004; SHRM, 2003). Authors have examined the effects of flexible work arrangements (Acker and Armenti, 2004; Kinman and Jones, 2008; Santos and Cabral-Cardoso, 2008; SHRM, 2003) on work-life balance. However, few authors (Ylijoki and Mäntylä, 2003) have focused on how work-life balance experiences are affected by their perceptions of time. Conceptually, this paper discusses how participants' experiences inform their deeper understanding of time. Empirical studies have demonstrated how time can create boundaries for workers (ibid). By contrast, in the case of academic employees (also called 'academics' in this paper) who benefit from increased spatial and temporal flexibility, work and non-work contexts are blurred. Contextual factors, linked to employment practice, such as working hours and schedules, can be more opaque because workers are often 'out of view.' In addition, workers become more autonomous in the creation of boundaries to carry out work- and non-work-related tasks. These parameters can be dependent on their ability to cope within temporal constraints. 
Participants in this case study were all full-time academic employees in a traditional Swiss University of Applied Sciences work environment. This has repercussions on their understanding of work-life balance. It also affects their experiences when a crossover and/or conflict of work- and non-work obligations occurs, which is evaluated in the following literature review.

\section{$2 \quad$ Literature review}

\section{The concept of work-life balance}

Work-life balance, as a concept, was first discussed in the literature in the late 1970s (SHRM, 2003). Kanter (1977), in her seminal work on work and non-work life in the US context, brought to light the difficulties to satisfy work- and non-work-related obligations. Schor's (1991) influential study, The Overworked American (Schor, 1991), underscored the trade-offs that are made between employees and employers in order to meet work-life balance expectations. At this time, the reciprocal, and often conflictual features of the worklife balance concept developed into a debate that would increase in importance over time. As work practices evolved, work-life balance needs influenced the implementation of flexible working arrangements and temporal flexibility (Madsen, 2006; Morganson, Major, Oborn, Verive, Heelan, 2009). The literature has continued to underscore that, in addition to work flexibility, effects of gender have also shaped the understanding of work-life balance as a concept.

The dimensions of the concept of work-life balance have been influenced by the role of women in the workplace and their growing difficulties of meeting work- and non-work demands (Acker and Armenti, 2004; Grzywacz and Carlson, 2007). Work-life balance has been translated by organisations into flexible work offerings (SHRM, 2003), which is centred on temporal and spatial work practices. These practices have hitherto been considered as benefits for employees (SHRM, 2003). By contrast, in the academic context, dimensions have not evolved in similar directions. Many non-academic sector jobs have developed work-life balance practices and integrated them into employment offerings (Acker and Armenti, 2004). Academic jobs have followed this trend to a lesser extent. Moreover, academics have fewer expectations in terms of work-life balance aspects of jobs (ibid). This is in part due to the nature of academic job roles, such as taking work home and publishing demands for promotion and/or tenure (Acker and Armenti, 2004; Ylijoki and Mäntylä, 2003).

Academic work, in particular the work of lecturers, has been set in traditional work contexts and work patterns (Gatta and Roos, 2004). This has been reflected in male-dominated organisational structures (Acker and Armenti, 2004), which are, in part, whence deeprooted expectations of workloads emanate. This has been influenced by the dual parent, 
single career household (ibid). These practices contrast with the increased work-life balance expectations of academic employees today. This reveals that although work-life balance practices have grown in non-academic sectors, academic employment practice has remained a laggard. A body of literature has emphasised that the lack of work-life balance perceptions for academics can lead to negative repercussions, such as burnout (Acker and Armenti, 2004; Santos and Cabral-Cardoso, 2008). Conceptually, the literature has focused on the work- and non-work-related roles of academics and how these roles can create conflict and tension, especially when crossover is experienced, which is discussed in the following section.

\section{Work-life balance crossover}

Authors (Grzywacz and Carlson, 2007, Kosseck, Baltes and Matthews, 2011; Kreiner, Hollensbe and Sheep, 2009) have expressed the view that work-life balance can be understood through a theoretical equilibrium between work- and non-work roles. By contrast, when work-life balance is dissected into its dimensions, it becomes clear that there is an opposing, dichotomous relationship that is, theoretically, incompatible. This suggests that neither work- nor non-work-related role satisfaction can be completely fulfilled because of an inevitable crossover of role-related duties. Despite this, work-life balance crossover is a situation that can be 'coped with' (Kosseck, Baltes and Matthews, 2011) to an extent by individuals. When viewing this theoretical equilibrium through a sociological lens, such as through the work of Merton's (1957) role set theory, role components overlap. Role set theory suggests that people carry multiple roles, related to work (such as the role of a colleague) and non-work (such as the role of a parent) contexts. Merton argues that the overlapping of responsibilities (work- and non-work-related) can create tension and, more specifically, what he called 'role conflict' (Merton, 1957). This can also be due to the nature of roles. It is precisely a perceived crossover of workers' responsibilities (work- and non-work-related) that can lead to this phenomenon.

It is unclear in the literature what specific dimensions constitute the perception of work-life balance crossover. Despite this, several authors discuss how schedule are used for work, and compartmentalised according to work tasks (Acker and Armenti, 2004; Doherty and Manfredi, 2006; Gatta and Roos, 2004; Grzywacz and Carlson, 2007; Ylijoki and Mäntylä, 2003). From one perspective, authors claim that crossover is perceived through the lack of a separation of roles (Ylijoki and Mäntylä, 2003), as discussed above. Alternatively, other authors (Kreiner, Hollensbe and Sheep, 2009; Ylijoki and Mäntylä, 2003) have discussed that traditional work/life boundaries in academic work are decreased when work invades private time, and vice versa, due to the independent nature of tasks (Acker and Armenti, 2004). Paradoxically, it is this same task independence that can generate 
negative effects of work in academia (ibid), in the form of work-life conflict, which is probed into in the next section.

\section{Effects of work-life conflict}

The literature highlights negative effects of decreased work-life balance, such as stress and burnout (Acker and Armenti, 2004; Friedman and Greenhouse, 2000; Lambert and Haley-Lock, 2004; Lewis, 2000; Moen and Sweet, 2004). Moreover, the manifestations of a lack of work-life balance have been debated in a related branch of the literature on worklife conflict (Kosseck, Baltes and Matthews, 2011; Kreiner, Hollensbe and Sheep, 2009). Work-life conflict is a concept that constitutes a lack of balanced work- and non-work obligations. The literature on the negative effects of work-life conflict in the academic sector has often focused on gender issues, such as schedule complexity for women who have conflicting work and family obligations (Acker and Armenti, 2004; Gatta and Roos, 2004; Santos and Cabral-Cardoso, 2008). There is a consensus in the literature that despite overwork becoming commonplace in academic work environments, academic employees function in a system that is no longer adapted to employee needs.

The core arguments in the literature have focused on the reciprocal exchange of task and available time in schedules (Kreiner et al., 2009; Ylijoki and Mäntylä, 2003). The debate has emphasised employee views of work-life conflict (Kinman and Jones, 2008; Kreiner et al., 2009), which is theorised by Merton (1957) through role conflict, as previously highlighted. Moreover, the general tenor of the debate has highlighted the lack of work-life balance initiatives by employers in academic work environments. It is unclear how worklife conflict affects academic institutions collectively, as workers have adapted to existing constraints, including temporal ones, which are evaluated in the next section.

\section{Understandings of time and work}

In sociology, the concept of time has been explored through the attempt to understand of its dimensions (Augé, 2014; Hall, 1989; Ylijoki and Mäntylä, 2003). Hall (1989), in his seminal work, The Dance of Life, discussed links between the understanding of time and completion of tasks. Hall (1989) identified the habituation of completing tasks one-at-atime (called monochronic) or simultaneously (called polychronic). This behaviour can be linked to cultural preferences (Hall, 1989). This explanation points out that time can be perceived in multiple forms, according to perceived crossover of tasks, task separation, and work pace. Moreover, it constitutes one dimension through which time and work allocation can be evaluated. Other authors (Kinman and Jones, 2008; Ylijoki and Mäntylä, 2003) have argued that time can be conceptualised in work according to type of work completed. This suggests that there are certain tasks that can be done according to non- 
temporal constraints. From a broader perspective, the above arguments reveal that time allocation for work can be altered, within constraints, by workers.

Sociologists have also argued that due to the ubiquitous nature of work, time cannot be measured in exact ways due to its opaque nature and an increase of worker mobility (Méda, 2004; Viard, 2011). Through the modernisation of work tools (such as non-face-to-face work methods using information technology), time is no longer exclusively based on faceto-face contact at the workplace, but rather through the accomplishment of tasks (Enlart and Charbonnier, 2013; Méda, 2004). This brings into question traditional work methods used to evaluate work quality and human input, such as work schedules, which are counted by hours, or increments of hours (Méda, 2004). Theories on the relationship between tasks, and the allocation of time to complete them, have been at the centre of debates in recent decades (Viard, 2011). However, the understanding of time in the context of worklife balance is more recent (Kreiner, Hollensbe and Sheep, 2009; Ylijoki and Mäntylä, 2003). Enlart and Charbonnier (2015) highlight that due to the permeating growth of technology, such as take up of social media and smartphones, time spent working is invaded by private time and vice versa. They further argue that the use of on-line social networks at the workplace, (for professional and non-professional uses), challenges current understandings of the effects of the work environment on employee socialisation (cf. Verdier and Colin, 2012). Time, in this sense, is no longer a viable measure of work, but rather a sort of vacuum into which work- and non-work activities are filled.

It is assumed that time is one avenue to perceive the managing of work- and non-workrelated obligations. Nevertheless, few studies have looked at how people's use of time is related to work- and non-work related constraints. One example is when people 'stretch' available time in order to meet obligations. This phenomenon occurs when workers attempt to fulfil work- and non-work-related obligations beyond reasonable boundaries. Boundaries can include aspects related to the individual situation of the worker, including stress limits, temperament, and preference of individual work versus team-oriented work. Understanding these boundaries can be conceptualised through a perceived control over work (Kinman and Jones, 2008). Despite this, workers are not autonomous in their attempt to manage time according to constraints; the constraints can be altered according to exterior factors (such as altered schedules and/or obligations). The literature discusses the importance of time management (Acker and Armenti, 2004; Gatta and Roos, 2004; Kreiner, Hollensbe and Sheep, 2009; SHRM, 2003; Ylijoki and Mäntylä, 2003), but lacks insight how the trade-offs of individuals affect their perception of time and perceived control when working.

This study looks into the case of academics working in Switzerland and how their views can provide deeper insight into this phenomenon in the context of two Swiss Universities of Applied Sciences. 
The literature reviewed supports the following research questions, which drive this paper:

1) How do academic lecturers understand work-life balance?

2) How do academic lecturers experience work-life balance crossover?

3) How do academic lecturers experience work-life conflict?

4) How is time conceptualised through the evaluation of academic lecturers' work-life balance-related experiences?

\section{$3 \quad$ Methodology}

\section{Case study approach}

Case studies, such as this one, are used to investigate a phenomenon in context (Yin, 2009). The use of an exploratory case study, according to Collis and Hussey (2009) is beneficial when there is a lack of theory. The case study approach is appropriate for this study because it attempts to derive insight and patterns from findings to provide richer understanding. Moreover, the conceptualisation of findings can lead to a better comprehension of the effects of work-life balance on academic employees in the Swiss University of Applied Sciences context. Nevertheless, exploratory case studies, do not attempt to generalise findings, but rather offer deeper situational understanding and validity (Creswell, 2003). Units of analysis in this study are academic employees. Findings, based on their work-life balance-related experiences, are analysed, in one case, through their qualitative replies. This type of approach inevitably involves increased subjectivity due to higher proximity with study participants during data interpretation.

\section{Participant profiles}

This study evaluates the work-life balance experiences of 11 full-time academic employees in two Swiss Universities of Applied Sciences. Employees in Swiss academic institutions have private law contracts and are not public civil servants. Tenure is not part of working conditions. There is a requirement for publishing, albeit not as extensive as in a researchoriented Swiss public university. Swiss Universities of Applied Sciences are not funded by the state, according to their research output. Their mission emphasises the link between theory and practice, with many academic employees involved in consultancy and applied research projects. Participants in this study were all volunteers and under no pressure, either directly or indirectly. On average, they had over 13 years' full-time academic work experience. One participant had fewer than two years' experience and two participants more than 20 years' experience. 


\section{Data collection}

Data were collected using open-ended questions in pencil and paper questionnaires. Questionnaires were pilot tested with three volunteers to evaluate their feasibility in June 2015. Profiles and key questions, derived from the literature on work-life balance (including understanding of work-life balance, perceptions of work-life crossover and work-life conflict), were included in questionnaires, with the possibility to fill them out electronically, upon request (email contact was provided with the initial email communicated to potential participants). Questionnaires were sent in August 2015 to a pre-selected number of academic employees, by email and paper, with an introductory text. The text provided and introduction to the purpose of the study and guarantees of anonymity and confidentiality. Access to academic employees was granted through informed consent in the email text. All contact information for potential participants was provided to the researcher through academic and professional relations. All communication with study participants was in English. An email was sent to each potential participant two days thereafter to confirm the purpose of the questionnaire and to provide contact details in case there were any enquiries. One reminder was sent by email ten days later. 11 out of an initial 15 questionnaires were returned, completed. All potential study participants were highly proficient in English, since it is also a language of instruction at the universities where they are employed.

\section{Data analysis}

Data from open-ended questions were transcribed into Word documents per question theme. Replies were analysed as an aggregate, using open coding (Creswell, 2003) to identify common themes. This is congruent with an inductive approach, which can lead to the development of future theory. In this study, themes that could be related to concepts were grouped and discussed in light of their conceptual features (also coded as themes). Furthermore, themes that could provide insight, despite divergence from common themes identified, were also selected and highlighted in discussions. This approach is congruous with inductive approaches used in exploratory studies, which emphasise a potential development of grounded theory (ibid). All data collected were kept anonymous. Quotes used in this paper therefore do not indicate types/levels of jobs (e.g., job title) or years of experience of participants in order to maintain total anonymity and confidentiality. Moreover, quotes in findings section were not selected according to number of appearances, but rather due to their insight and meaning, which can support greater understanding through their conceptualisation.

\section{Role of the researcher}

Findings in this paper were not only interpreted to retrieve their meaning, in a strict sense, but rather filtered through the subjective view of the researcher. In essence, this is a study on academics carried out by another academic. Qualitative researchers have understood 
this approach through the insider concept (Dwyer and Buckle, 2009), which suggests that the proximity of a researcher is related to their ability to 'connect' with study participants. This approach is also supported by the role of solipsism, or one-selfism (Fay, 1996). Solipsism suggests that there are deeper implications of the interpretation of findings when the researcher can position their understandings of replies because they have lived experiences in the same context. Furthermore, Merton (1972) argues that there is deeper contextual understanding of findings because of strengthened robustness of qualitative data interpretation. Findings in this paper are interpreted through these two lenses: one through the perspective of the study participant, and the other through the contextual understanding of the researcher, who works in the same study environment in a similar role as study participants. This approach, inherent to qualitative data interpretation, can also be enacted in writing style, which can adopt voice of the first person, for example. Despite this argument, discussions in this paper use a more distanced, formal writing style, which is appropriate for this type of academic paper.

\section{$4 \quad$ Findings}

\section{Understandings of work-life balance}

Participants illustrated understandings of work-life balance through the simultaneous accomplishment of multiple tasks. Replies emphasise the need to fulfil work- and nonwork-related obligations.

"Being able to be a good parent, friend, and employee, all at the same time."

"Being able to concentrate on work at work and home at home."

Replies also show that there is the need to compartmentalise work and non-work tasks. This also underscores a need for mental separation between tasks and the importance of task relationship to contextual factors. One example is the link between task and the location where the task is carried out.

"It is when you have accomplished your tasks at work and your mind is free from worries."

"It means that work should not take over your life."

Work-life balance understandings are also related to benefitting from periods of time to focus on work and/or on personal life.

"Having quality time for work and home."

"If you have lots of home/personal problems, you may not be able to give $100 \%$ at work." 
The above findings reveal that work-life balance is perceived through sets of work- and non-work obligations. In on academic context, findings highlight worker autonomy and benefits of flexible schedules. Findings provide contrasting evidence to current understandings of work-life balance because of profession-related aspects of jobs (such as in the case of academia). Difficulties meeting work- and non-work obligations can arise because of incompatible schedules, which is one focus of the next section.

\section{Perceived effects of work-life balance crossover}

Work-life balance crossover is perceived when time is not available at either work, or at home. This situation requires compromises from workers.

"When extra hours are needed and when family time is compromised."

Perceptions of work-life crossover also can cause undesirable health-related effects.

"Feeling stressed, anxious."

"Bringing work home... and it starts to affect your health."

Schedule complexity is generated due to increased work- and non-work obligations. Despite attempts to manage tasks through the attribution of allotted time, unpredictable work schedules can cause 'interference.'

"Interference can occur because of time management."

Feelings of resentment at home can also grow, due to work-life balance crossover.

"You can feel guilty about bringing work home."

"After hours work can negatively affect family life."

"Partners may not understand about the amount of work time takes up."

Findings suggest that work-life balance crossover is difficult to control for academic employees. Despite attempts to organise tasks, such as through time management (as one method), perceptions of work-life balance crossover generate consequences on nonwork spheres, such as the family. This situation can be conceptualised through the emergence of unforeseen role obligations that can lead to perceived overload. Again, when viewed through role sets, this increased load of obligations can produce negative outcomes, which are discussed in the next section.

\section{Outcomes of a lack of work-life balance}

Home-related consequences, due to a lack of work-life balance, have been the focus of studies. In this vein, results of a lack of work-life balance are illustrated by negative experiences in family life. 
"Pressure on family."

"Family life can suffer."

"You can destroy your family, your life, and yourself."

Health-related effects are epitomised through employee burnout, which has been widely discussed in the literature. These effects include the psychological well-being of workers. In turn, this situation can have negative repercussions on work and non-work life. Effects can be perceived, in part, as predictable outcomes of working conditions in academic sector jobs, due to mental overload.

"Stress, worries, lack of sleep."

“Illness, impatience, nervous."

"Stress, depression, anxiety."

Workers can experience negative consequences of a lack of work-life balance in terms of their psychological and physical well-being. The previous findings reveal that a lack of work-life balance affect the worker in addition to people who hold relationships with them. Findings underscore that negative effects of work-life balance are radiated to family relationships. These effects can also emanate from temporal aspects of work, which are discussed in the next section.

\section{Understandings of time}

Replies emphasised the importance of fragmenting time according to schedules. Moreover, participants highlighted the necessity to organise their time according to constraints, such as others' schedules.

"Structuring the day, time management (using to do lists)."

"Inability to make appointments, e.g., dentist. Inability to make phone calls when others have tight timetables."

One reply recalled the importance of adapting to work and non-work rhythms.

"Be able to adapt work timing to own life and pace."

Interestingly, participants evoked the ubiquitous nature of work and the possibility and/or necessity to work anytime, which can lead to added pressure on work-life balance.

"Work is never finished (it never feels finished)."

"Work-life balance does not exist for me. When your employer can contact you anytime, there cannot be balance." 
Replies were also revealing in terms of the assumptions related to carrying out academic work, such as the requirement to take work home. Replies suggest that academic work is not fragmented, but rather a continuous process. Findings point out that academic work is not comprised of sets of tasks that can be completed separately, but rather are unequally dispersed over long periods of time. Findings also imply that participants need to be attentive to work needs on a continual basis.

"Teaching, for example, cannot be left at work; there is always some preparation to be done."

"Always some preparation needs to be done."

Interestingly, findings shed deeper light into academic employees' perceptions of time. The ubiquitous nature of work-related communication (such as through email and/or other asynchronous/synchronous electronic tools) reveals that work can be carried out anytime. Findings suggest that employees seek to maintain professional and non-professional roles within dynamic sets of constraints. Conceptually, this indicates that academic workers' perceptions of time are formed through these constantly changing constraints. One example is when attempting to manage complex schedules, with constraints that are beyond the control of workers (as indicated in replies).

The interpretation of findings in previous discussions was reinforced by the researcher's contextual experiences, from working and interacting with academics in a similar job environment. The researcher's ability to relate to findings brought increased understanding of the meaning of replies that would have otherwise remained 'on the surface.' The interpretations of participants' replies in above discussions collectively reveal deeper conceptual insight into understandings of the influences that shape perceptions of work-life balance, which is discussed in the next section.

\section{$5 \quad$ Conclusions}

\section{Work-life balance perceptions are dependent on context}

Findings from this study suggest that factors related to the understanding of work-life balance are contextual dependent. This means that perceptions are not only formed by individuals, but also through common experiences in their employment environment. One example that was brought to light in findings is the importance of workspace. Despite the flexibility that academic work provides, such as flexibility to alter work time and space (visà-vis non-academic work environments), the understanding of academic workspace has created a contextual environment where work is ubiquitous. This situation can have unforeseen consequences on the well-being of workers, such as the inability to 'switch off.' This is illustrated in difficulties generated by work-life balance crossover. Conceptually, 
negative consequences of this crossover emanate from the blurring of mental boundaries, which are, in part, perceived through context. This context forms the perception of workspace, which has hitherto been a physical location, often in a building, or premises, located outside of, or at home. This understanding is challenged by current work practice, which includes the use of virtual electronic tools.

The perception of workplace context is formed, in part, through the use of face-to-face and non-face-to-face interaction of workers. In the case of work-life balance perceptions, this suggests that context is composed of mental cues, which structure perceptions of the workplace. Cues can be related to interaction with colleagues, being located in an office space, and working in institutional buildings. When probing into how work-life balance is understood by academic lecturers, there are decreased mental cues, as their work environments, their perceptions of it, are constantly altered because of their increased spatial and temporal flexibility. One repercussion of this situation is the increased need to adapt to new contexts and to organise complex schedules, with multiple constraints.

\section{Work-life balance perceptions can be influenced by professional practice and employment sector tradition}

Findings confirm debates in the literature that underscore the influence of tradition in academic work practice. There is a conventional understanding that requirements of academic work include carrying out tasks outside of the institution. This reduces face-toface presence and affects perceptions of workloads since academic employees are not always 'seen' working. The literature reveals that the pace of work requirements has increased more quickly than the employment policies of academic institutions. Academic institutions retain employment traditions that were developed during periods of dual parental, single career families and a lower usage of electronic tools to work at a distance. Contextually, this situation has deeper repercussions on how the academic employment sector attracts and retains employees, in the case of lecturers. From a conceptual standpoint, this suggests that employer and employee expectations have diverged. This is manifested through the negative effects of role incompatibility when academic employees' work- and non-work-related responsibilities coincide and/or conflict. When put into an academic work environment context, findings cast doubt on the effectiveness of current work practice because employers can remain unaware of the causes of a lack of work-life balance for employees. The successful accomplishment of academic work appears to have greater costs than benefits for academic employees.

When viewed through a close evaluation of costs and benefits, workers use trade-offs to avoid what Merton (1957) called role conflict because of incompatible role sets. In this sense, workers attempt to maintain favourable aspects of their roles and eliminate unfavourable ones. Aspects related to roles can include childcare, in the case of a family role, or interaction with colleagues, in the case of a collegial role. This phenomenon 
suggests that role exchange is not static, but rather an active process that is constantly adapted to contextual factors. When work-life balance is examined through the trade-offs within role sets, workers actively attempt to attain role satisfaction.

\section{Workers' perceptions of time are incompatible with their attempts to meet work- and non-work obligations}

Findings bring to the surface indications that academic employees face trade-offs in their pursuit of attaining work-life balance. These sets of trade-offs are linked to career choice (such as having increased spatial and temporal work flexibility vis-à-vis work with more regular, office-based schedules). Trade-offs are understood through sets of obligations that academic employees strive to meet, within boundaries. One external influence that affects perceptions of work-life balance attainment (or not) is pressure from not being able to 'switch off.' When probing into how academic employees make choices, there is the overriding influence of internal drive, which can lead to overworking. This argues that academic work achievement is influenced by intrinsic factors (such as workers' personal characteristics). An academic work context's flexibility (which can be considered a benefit), can also have negative consequences on the well-being of workers. This denotes that a lack of mental boundaries, within which trade-offs can be made, can generate stress and, ultimately, burnout (cf. Acker and Armenti (2004)). Conceptually, these boundaries can also be influenced by perceived worker control (cf. Kinman and Jones, 2008), which suggests, again, that workers actively participate in making trade-offs.

When viewed through monochronic and polychronic task management (cf. Hall, 1989), academic workers attempt to complete tasks according to time slots into which they try to 'fit' as much work as possible. However, findings also reveal that aspects of this type of time management are hindered by schedules beyond the control of workers. Findings point out that in academia, the lack of work-life boundaries allows work- and non-work-related obligations to crossover frequently. Examples from academic workers illustrate the emergence of 'stretched' schedules. This means that the fragmentation of work can extend to all areas of work- and non-work-related contexts. Notably, findings underscore the perception that there is an expectation to accomplish work outside of academic institutions. There is a tendency to 'fill' open slots when work can be achieved, regardless of location. This puts forward the argument that there are two factors to consider when evaluating the relationship between time and work. The first one focuses on the conditions external to the worker, such as time availability and workspace. The second factor relates to the personal characteristics of the worker, such as levels of perceived control and resilience to stress. Investigating and evaluating the effects of time and space for academic workers requires probing into phenomena that can remain embedded in the mind sets of people. Such as in this study, effects can be explored more deeply by through gaining insight into the academic work context and actors within it, in situ. 


\section{$6 \quad$ Limitations and further research}

This study is limited to academic employees in one context. Furthermore, its scope is limited by a hand-picked purposive sample. For future studies, a larger group of employees from a larger number of Swiss Universities of Applied sciences could provide deeper insight. Open-ended questionnaires could be complemented by interviews to gain deeper insight into employees' experiences. In future studies, the contribution of co-authors could increase depth and decrease subjectivity in the interpretation of replies. Moreover, participants from the different linguistic regions of Switzerland could provide a more coherent representation of the country and highlight cultural disparities.

\section{References}

Augé, M. (2014) Une ethnologie de soi. Le temps sans âge. Paris: Editions du Seuil.

Acker, S., Armenti, C. (2004) "Sleepless in Academia," Gender and Education, Vol. 16, No. 1, pp. 3-24.

Collis, J., Hussey, R. (2009) Business Research: A Practical Guide for Undergraduate and Postgraduate Students. Basingstoke: Palgrave Macmillan.

Creswell, J. (2003) Research Design. London: Sage.

Doherty, L., Manfredi, S. (2006) "Action research to develop work-life balance in a UK university," Women in Management Review, Vol. 21, No. 3, pp. 241-259.

Dwyer, S., Buckle, J. (2009) "The Space Between: On Being and Insider-Outsider in Qualitative Research," International Journal of Qualitative Methods, Vol. 8, No. 1, pp. 54-63.

Enlart, S., Charbonnier, O. (2013) A quoi ressemblera le travail de demain? Paris: Dunod.

Fay, B. (1996) Contemporary Philosophy of Social Science. Cambridge: Blackwell.

Friedman, S., Greenhaus, J. (2000) Work and Family- Allies or Enemies? Oxford: Oxford University Press.

Gatta, M., Roos, P. (2004) "Balancing without a net in academia: integrating family and work lives," Equal Opportunities International, Vol. 23, No. 3/4/5, pp- 124-142.

Grzywacz, J., Carlson, D. (2007) "Conceptualizing Work-Family Balance: Implications for Practice and Research,” Advances in Developing Human Resources, Vol. 455, No. 9, pp. 455-471.

Hall, E. (1989) The Dance of Life. New York: Anchor Books.

Kanter, R. (1977) Work and Family in the United States: A Critical Review and Agenda for Research and Policy. New York: Russell Sage Foundation.

Kinman, G., Jones, F. (2008) "A Life Beyond Work? Job Demands, Work-Life Balance, and Wellbeing in UK Academics," Journal of Human Behavior in the Social Environment, Vol. 17, No. 1-2, pp. 41-60. 
Kosseck, E., Baltes, B., Matthews, R. (2011) "How Work-Family Research Can Finally Have an Impact in Organizations," Industrial and Organizational Psychology, Vol. 4, pp. 352-369.

Kreiner, G., Hollensbe, E., Sheep, M. (2009) "Balancing Borders and Bridges: Negotiating the Work-Home Interface via Boundary Work Tactics," Academy of Management Journal, Vol. 52, No. 4, pp. 704-730.

Lambert, S., Haley-Lock, A. (2004) "The Organizational Stratification of Opportunities for Work-Life Balance," Community, Work \& Family, Vol. 7, No. 2, pp. 179-195.

Lewis, S. (2000) "Restructuring workplace cultures: the ultimate work-family challenge?," Women in Management Review, Vol. 16, No. 1, pp. 21-29.

Madsen, S. (2006) "Work and Family Conflict: Can Home-based Teleworking Make a Difference?," International Journal of Organization Theory and Behavior, Vol. 9, No. 3, pp. 307-350.

Manfredi, S., Holliday, M. (2004) "Work-life balance: an audit of staff experience at Oxford Brookes University," Oxford Brookes University, Center for Diversity Policy Research, retrieved 15 June at http://www.brookes.ac.uk/business/research/cdpr

Méda, D. (2010) Le Travail. Paris: Presses Universitaires de France.

Merton, R. (1957) Social Theory and Social Structure. Glencoe: Free Press.

Merton, R. (1972) "Insiders and Outsiders: A Chapter in the Sociology of Knowledge," American Journal of Sociology. Vol. 78, No. 1, pp. 9-47.

Moen, P., Sweet, S. (2004) "From 'work-family' to 'flexible careers'," Community, Work \& Family, Vol. 7, No. 2, pp. 209-226.

Morganson, V., Major, D., Oborn, K., Verive, J., Heelan, M. (2009) "Comparing Telework locations and traditional work arrangements. Differences in work-life balance support, job satisfaction, and inclusion," Journal of Management Psychology, Vol. 25, No. 6, pp. 578-595.

Santos, G., Cabral-Cardoso, C. (2008) "Work-family culture in academia: a gendered view of work-family conflict and coping strategies," Gender Management: An International Journal, Vol. 23, No. 6, pp. 442457.

Schor, J. (1991) The Overworked American. New York: Basic Books.

Society for Human Resource Management (SHRM) (2003) "Work/Life Balance: Challenges and Solutions," SHRM Research Quarterly, January.

Verdier, H., Colin, N. (2012) L'âge de la multitude. Paris: Armand Colin.

Viard, J. (2011) Eloge de la mobilité. Le Tour d'Aigues: Editions de l'Aube.

Yin, R. (2009) Case Study Research: Design and Methods. Thousand Oaks: Sage.

Ylijoki, O.-H., Mäntylä, H. (2003) "Conflicting Time Perspectives in Academic Work," Time Society, Vol. 12, No. 1 , pp. 55-78. 